\title{
ARTE AMBIENTAL: FORMAS RELACIONAIS NA MODELAGEM DOS LUGARES
}

Isabela Frade ART/UERJ

\section{RESUMO}

Apresentam-se as perspectivas de desenvolvimento de um projeto de intervenção artística cujo sentido se constitui pela criação de uma zona aberta e colorida no morro da Mangueira no Rio de Janeiro. Nessa modelagem do lugar, gesta-se um trabalho de arte relacional na proposição de momentos de encontro e produção de objetos para troca e contato interpessoal. Abrimos terreno para a colaboração mútua em processos criativos e reflexivos, ambos calcados na consciência ambiental pelo enlace afetivo amplificado com o espaço e a coletividade ao entorno. Seus participantes estão envolvidos na integração comunidade/escola/universidade praticando a aproximação entre o saber acadêmico, especializado, o saber docente, amplo e escolarizado, e os saberes comunitários, enraizados nas formas vitais do cotidiano e preservado em sua memória local.

Palavras chave

Arte relacional, esfera pública, formas de saber, comunidade.

\section{ABSTRACT}

The prospects of a continued artistic intervention project are presented. Their meaning lays on the creation of an open and collorfull zone at Morro da Mangueira in Rio de Janeiro. In this place modeling, we engender a relational art work trough the proposition of moments for acquaintancy and object production for exchange and interpersonal contact. The research reveals creative and reflective processes involved in environmental awareness, as well as the amplified union of the emotional with the space and the surrounding community. The participants are involved in integrating community / school / university by practicing the approximation between academic knowledge, with its expertise, the teaching knowledge, broad and formal, 
and the community awareness, rooted in the vital forms of everyday life and preserved in its local memory.

Key words

Relational art, public sphere, forms of knowledge, community.

\section{Da modelagem do encontro}

As investidas criativas, daquelas que nos salvam da permanência com apenas o que já é conhecido, são quase sempre vacilantes e, como um movimento pendular, no recuo é que avançam, e se fazem prosseguir continua e sutilmente enquanto tateiam, com saboreio, uma paisagem inaugural. Elas precisam se fazer com cuidadoso controle especialmente se tratam de envolvimento com os demais, de conexão com pessoas e, mais especialmente, se com as quais não se tem proximidade ou conhecimento anterior. A violência pode ser evitada, e ainda que o incômodo seja algo naturalmente advindo dessa progressão, será minorado se manejado com reserva.

A voracidade contemporânea, a pressa sem limites da via do produzir a quantidade, do costumeiro passar sobre a via expressa do instituído não permite a condição para o encontro do íntimo. Para isso, é preciso o passeio, a divagação e a espera. A mudança de estado pressupõe esse vínculo com o que nos aguarda no novo contexto, como se o mundo pudesse subsistir, inadvertidamente e verdadeiramente, em um lugar fora do tempo. É como se o existir acontecesse como algo fortuito, seu segredo não se deixa capturar na conivência com a lógica do cálculo e da previsão funcionalista. Nesse movimento de distanciamento da usura fatigada, no qual tudo é apenas objeto de consumo aflito, mal processado, se alcança um estado de disposição sensível ampliada. Esse estado está identificado como condição básica para se viver a integralidade da arte.

De um momento para além do ordinário, do ajustado, se instala a arte viva. Com isso, porém, este gesto não se distancia do que é comum, mas que requer, ao contrário, desenvolvê-lo pelo outro sentido, ou lado, do existir, do ser em estado interiormente ativo. Assim, poucas são as coisas que se exigem nisso, apenas a 
distensão nua (para lembrar um termo caro a Agamben e dizer desse estado sem usar a noção de pureza nem a de simplicidade, pois que não combinam com a complexidade do mundo).

Vida como força expansiva, consciente e sensível, plenitude em desejo. Tampouco requer a solidão, nem o estado em separado da contemplação. Se com ela não se incomoda, entretanto, fabrica a agremiação pela energia do encontro. 0 sujeito vivo inquieta-se, instiga e intervém no mundo. Implica o outro numa aproximação. Há algo de si que não lhe cabe, contudo, transbordando para os outros. Reverbera-se. Espelha-se. Nessa abertura se deixa levar, e no seu próprio vácuo, o outro penetra, vivificando-o desde dentro. Pode-se chamar isso também de amor, pela adesão e conformação emocional desse processo.

Por isso o delicado vagar à disposição do outro se apresenta como premissa para a reunião a partir de valores inaugurais, onde o estado da arte é mesmo o mote: é o estar em ação no compartilhamento sensível, é se postar como agente na criação de experiências, memórias e conhecimentos vitais e fazê-los reconhecidos através de formas eloquentes. Essa situação é também educativa, pois profundamente transformadora.

Nesse sentido, e pensando nessas produções de arte a partir das perspectivas da arte pública, devemos entender que assim se afirmam as proposições onde o agenciamento coletivo integra o projeto desde o começo, desde seu ponto de partida. Exige, por sua vez, para seu operar, uma condição própria para que se produza, então, o enlace: em que propositores se postam em situação de troca em participação simétrica.

Entendo que a melhor estratégia para seu deflagrar seja a gestação do elo através de um tema comum, capaz de propiciar uma identidade coletiva. $\mathrm{Na}$ discussão sobre um determinado conteúdo construída por elemento significativo a todos, distendendo-o sobre as diferentes óticas pessoais, se produz esse modo inicial. Assumo o postulado de Maturana e Verden-Zoller (2009) de que nossa existência humana se produz na linguagem, na vida imersa no conversar e considero em primeiro plano esse substrato relacional: "Sustentamos que todo o viver humano acontece em redes de conversação" (p.9). 
Essas ideias se apresentam como formas reflexivas experimentadas em um processo de trabalho coletivo, quando me dispus, em conjunto com mais 18 mulheres, a criar uma zona de colorido no morro da Mangueira, no Rio de Janeiro. Um campo de energia afetual que corre fluido, e delicadamente, pretendendo manter ligada a comunidade à universidade, UERJ, onde leciono. Uma mistura de pessoas de diferentes lugares da cidade, ainda que antes planejasse unir mangueirenses e uerjianas apenas e jogar com essa dualidade favela $x$ universidade sob o espectro social do gênero. Aprendi que de favela não se deve falar, é termo preconceituoso, estigma. Essa palavra que fere onde se coloca o desígnio comunitário - por isso comunidade. E exprime o fato de que a universidade recicla rapidamente os sujeitos: correm os estudantes, no fragmentário processo de formação profissional, a diferentes sequências desconexas, e não há como propor um jogo mais denso nem mais demorado sem a devida abertura a novas pessoas. Reconheço que o tempo universitário é ligeiro, curto, e os contatos são quase inteiramente superficiais e frios.

O grupo se faz e refaz desde 2009, quando se formou, e segue agenciando integrantes ou as desligando, se transformando continuamente. Importante notar que se apresentou, faz cerca de um ano, um senhor respeitável, incrível sujeito, que se interessou pelas questões do coletivo. Essa ideia de brincar com o gênero foi o ponto de partida, pois seria o ponto de flexão dos dois grupos formadores: somos os que pensam o feminino de cá ou de lá, manifestando, naturalmente, coisas comuns, ainda que sejam grandes as diferenças entre nós. Partilhamos revoltas domésticas, fracassos de dons sociais e dotes naturais. Vivemos uma corporeidade feminina, marcadamente magoada pelo orgulho machista dominante. Divergimos em nossas histórias de vida, em nossas ambições e em nosso desejo pela arte. O mais incrível nessa experiência de troca continua foi o convergir de afinidades mais profundas com o grupo mangueirense: não querem a arte pela arte, querem a arte para a vida, seja para embelezar a casa, ser útil no dia-a-dia ou para mudar a condição de alguém ou de algum lugar. Nessa praticidade animada, que se uniu ao romantismo das jovens artistas da universidade, gestamos o projeto Terra Doce, na motivação por constituir espaços de beleza e de comunhão. 


\section{Da modelagem do lugar}

Ao planejar a intervenção que pretende ir além de causar efeitos imediatos, percebo que essa exige constância e investimento contínuo. Na aproximação onde a alteridade é grande, gestos devem ser elaborados pelo prazer da aproximação com a diferença sem injúria. O termo doce explicitava essa condição na união. Em que o objetivo era apenas esse: o encontro, o estar junto. De início, essa travessia entre Uerj e Mangueira era frequente e, até a formação do grupo que eclodiu no coletivo, eu estava sempre indo e vindo, promovendo oficinas de arte (desenho, colagem, modelagem) na Mangueira. A violência, diariamente, explodia no morro com vigor. Decidimos fixar o encontro na UERJ, onde estávamos mais protegidas. Mas a ideia de envolver o morro permanecia, e sonhamos juntas com a criação de um lugar de encontro - primeiro um atelier e depois uma praça. Esse atelier teria ferramentas e barro, seria também uma galeria para mostrar nosso trabalho. E essa praça teria bancos e flores, lugares para nossas crianças e velhos. Descobrimos que nós, mulheres, queremos sempre envolver a todos, e precisávamos de um território livre, aberto para reunir familiares e conhecidos, e juntas discutimos a proposição de um jardim, a que em princípio denominamos Jardim das Delícias. Encontramos um espaço aberto para a eclosão dessas ideias defronte a uma pequena creche escola, em uma rua que se repartia em duas grandes escadarias e que continha, em seu meio, patamares verdes, com mato e lixo.

Colhemos algumas notas na história oral do lugar: faltando verba para a finalização da curta Rua Icaraí, o poder público decidiu criar ali uma dupla escadaria, evitando o uso do asfalto e ocupou, em meio ao par de escadas, canteiros entre platôs acimentados mobiliados com bancos e mesas de xadrez. Foi nesse pequeno lugar, que vimos tomado pelo monturo de lixo conhecido como "pracinha do crack", que pudemos vislumbrar um recanto para "o jardim". Nessa pequena abertura procuramos estabelecer o vínculo mais profundo e vasto entre UERJ e Mangueira, agora firmando o nosso projeto de interação no próprio morro.

Revendo esse processo, desde 2008 estamos, pouco a pouco, construindo uma passarela de afetos entre ambos, tendo sido interrompida muitas vezes essa obra pelos acessos de violência que ocorrem no entorno. Em 2009, esse trabalho, na forma do projeto Terra Doce, se dava na sede da ONG Casa das Artes da 
Mangueira. Daí se origina o grupo que formou o coletivo misto de mulheres mangueirenses e uerjianas, O Círculo. Pelos ataques de violência progressivamente acirrados, decidimos migrar o grupo para o atelier de cerâmica da UERJ, onde se fixaram, semanalmente, momentos de criação, encontro e troca.

A criação do coletivo foi uma estratégia de produzir um material misto de partida: as proposições de arte já seriam assim frutos das duas partes, onde não haveria a imposição nem privilégio da universidade sobre a comunidade. Trabalhamos contra a hierarquia de saberes, buscando compor relações a partir de uma composição simétrica, todos envolvidos nas trocas e aceitação da experiência do outro. No entanto, a proposta era voltar a agir na comunidade e não permanecer fixadas no campus.

Foi o monte de lixo jogado sobre os canteiros, e que deixava ainda o verde à mostra, que nos permitiu o contato com a Creche Escola Nação Mangueirense (SME), quando nos dispusemos cuidar do terreno em frente, e constituir um novo lugar para que pudéssemos criar um trânsito melhor das crianças e seus familiares no acesso diário à creche. Pensamos em iniciar exatamente pelo patamar central e nos canteiros ladeados por onde se dá a entrada e saída para a escolinha. Depois de um ano (2011) de negociações entre diferentes instâncias pessoais e institucionais, pudemos iniciar em junho os trabalhos práticos e agora lá já existe um jardim. 


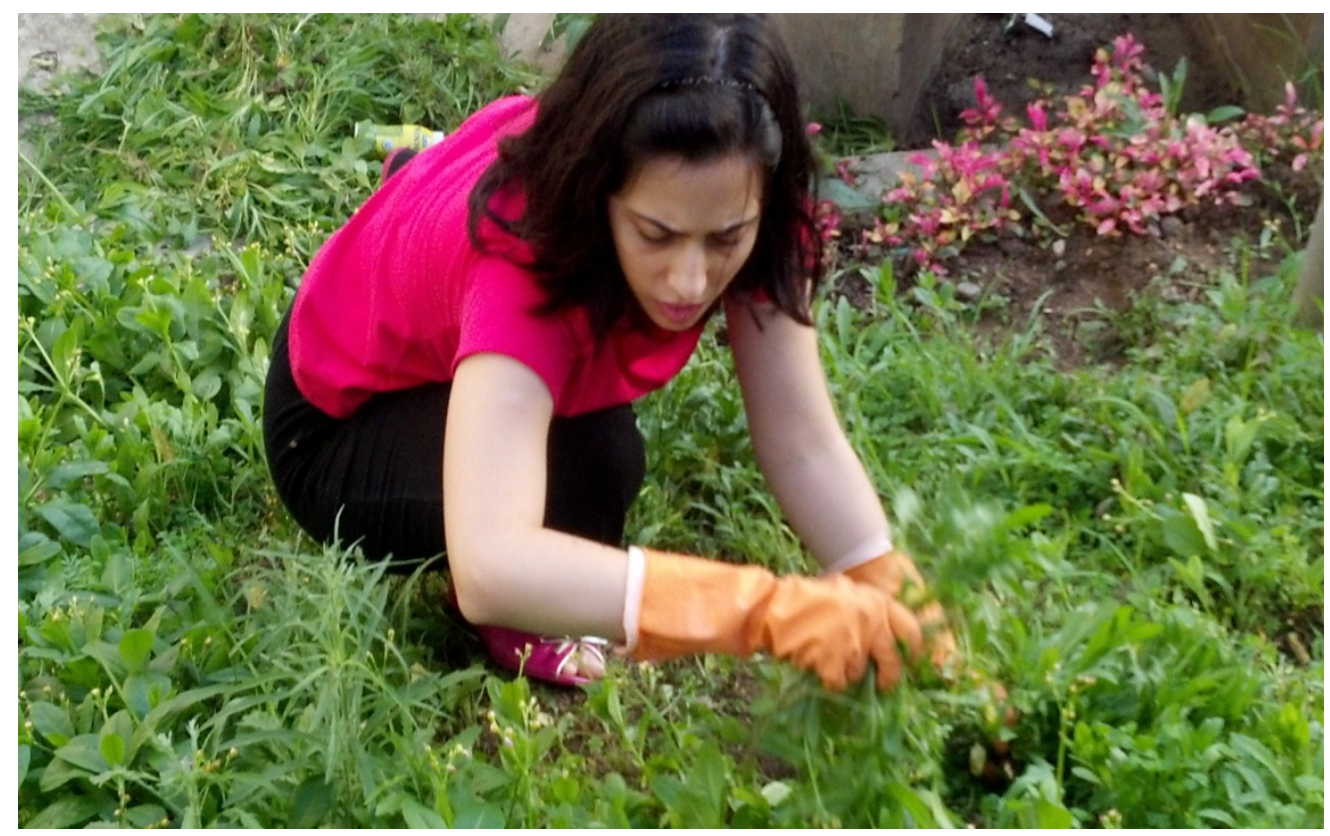

Fig 1. Colhemos as primeiras flores, numa boa surpresa: o Jardim das Delícias é fértil! $<$ Arquivo: Fonte da pesquisa.>

Considerando a perspectiva de educação como ação política, como exercício de troca dialógica e crítica social praticado em espaço de liberdade (Freire, 2010), constituímos um projeto de arte focado na abertura de um lugar de interação da equipe de pesquisadores artistas em um sub projeto, o ARTE VIVA, vinculando a universidade com a comunidade Mangueirense em seu sentido mais pleno. No desejo de ativar a plasticidade criativa do espaço em dinâmicas artísticas abertas, estabelecemos uma abordagem não disciplinar, mas de busca randômica pelos saberes que eram politicamente interessantes para a consolidação do grupo de artistas e seu aprendizado nas formas de arte pública. Se trata de criar a partir de um espaço física e socialmente degradado, um lugar de convívio. A permuta se desenvolveu, como opção tácita pelo contexto de violência acirrada, na criação de um programa educativo com a Creche Escola Nação Mangueirense.

A se creche localiza bem próximo à Rua Visconde de Niterói, zona fronteiriça com o asfalto das grandes vias ao pé do morro. Essa sub região é conhecida como "Buraco Quente". A CENM atende cerca de uma centena de famílias, recebendo bebês de três meses e atendendo-os até a faixa de quatro anos. Nos dispusemos `a parceria pela oferta de oficinas de construção e modelagem em cerâmica e outros materiais. As oficinas se apresentariam voltadas para os pequenos mas também para os docentes, como espaço de criação livre e/ou integrado às atividades 
pedagógicas desenvolvidas pela instituição. Com vistas a nos mostramos ativas na comunidade escolar como um todo, já nos solicitam regularmente para atuar nas ocasiões das festas comemorativas e nas reuniões com os pais.

Essas ações contribuiram especialmente para o adensamento das relações comunidade/escola, trazendo a arte na aproximação entre o saber acadêmico, especializado, o saber docente, amplo e escolarizado, e os saberes comunitários, enraizados nas práticas vitais do cotidiano e preservado em sua memória local. Nessa aproximação e enlace, gestamos uma nova etapa no projeto de arte relacional. Aqui estão formuladas questões estéticas em dispositivos relacionais nos quais, apostamos, serão revelados os processos criativos e reflexivos a serem derivados em uma consciência ambiental. O enquadramento se faz dirigido pelo que toca o envolvimento afetivo amplificado com o espaço e a coletividade ao entorno, incluindo aí, como espaço disponível à relação, a própria universidade.

Visamos preservar e dinamizar os acervos artístico, natural e sociocultural da Mangueira em seu diálogo com a universidade que, por sua vez, é campo de incentivo à constituição de intervenções na sensibilização e humanização das suas relações, na superação de seu ambiente frio e despersonalizado. A escola aparece como um ponto de encontro, como matéria de amálgama entre saberes de lá e de cá.

\section{Dos saberes em troca e as dinâmicas relacionais}

As duas comunidades, uerjiana e mangueirense, são ricas em tradições e saberes, entretanto fechadas em suas próprias redomas epistêmicas e políticas, com extensas barreiras sociais que as mantém afastadas. Essas realidades apartadas que se confrontam em espaços tão próximos instigam os pesquisadores e artistas a uma progressiva aproximação. O coletivo de arte O Círculo vem operando como dispositivo deflagrador de envolvimento mútuo por meio da troca de saberes e fazeres, tendo na produção estética feminina em cerâmica o seu laço. O barro é identificado em seu aspecto sensual, é a "carne da terra", matéria macia que recolhe o toque e se deixa modelar. 


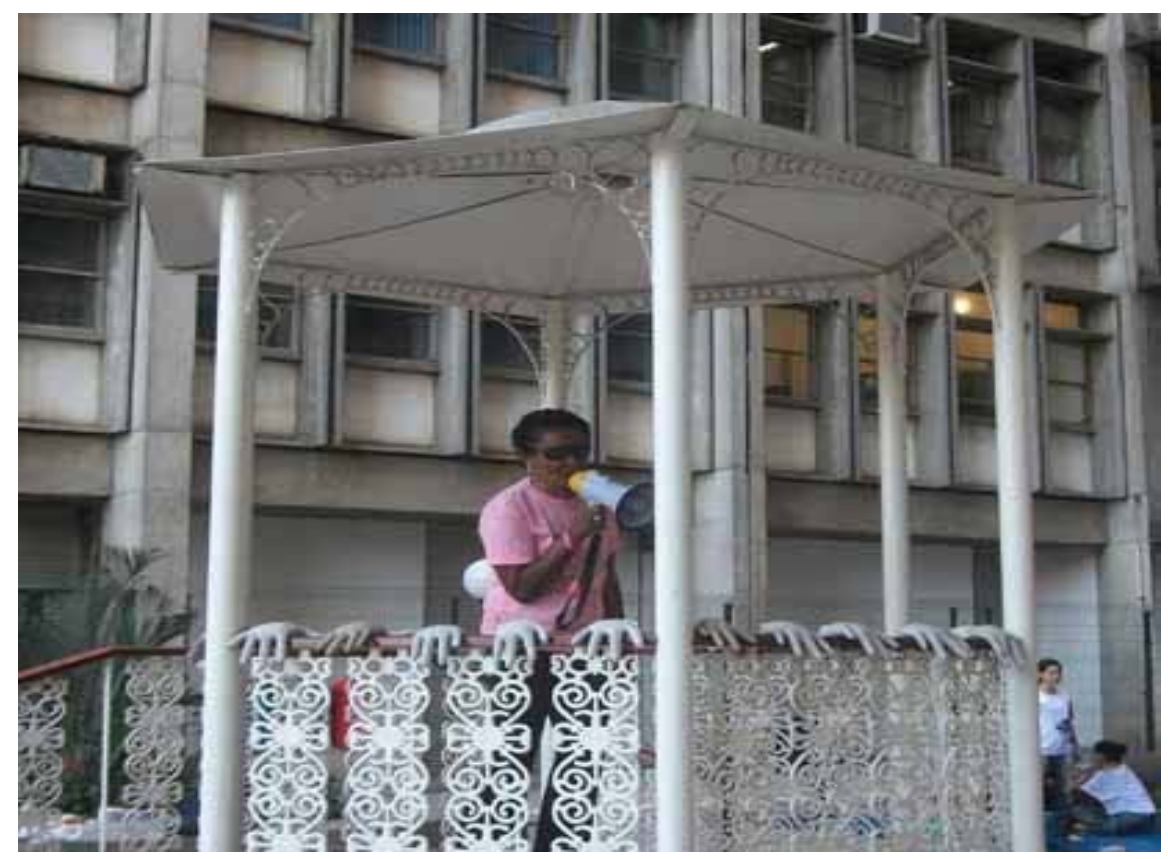

Fig 2. A poeta mangueirense Helena Sá declama no coreto da Praça da Democracia, campus UERJ Maracanã. Fonte: arquivo da pesquisa.

A universidade, operando como importante centro de produção científica e cultural, investe em algumas ações politicamente orientadas como abertura em seu nicho de instituição oficial. Alguns projetos acadêmicos estão vinculados à ações de aproximação e reflexão em contato direto com a sociedade. Em nosso levantamento inicial, conseguimos fazer contato com alguns mangueirenses que integram o corpo acadêmico como alunos, funcionários ou usuários dos serviços da universidade. Estamos constituindo pouco a pouco modos de coparticipação em nossas intervenções. Esse processo é delicado, pois a Mangueira hoje é palco de ação de severa política pública de segurança na implantação de uma UPP - Unidade de Polícia Pacificadora. O Estado dispõe ação policial ostensiva mantendo a comunidade sob estado de vigilância, impedindo o domínio do tráfico na localidade.

\section{Dos laços institucionais}

Atento a essa dinâmica, o grupo de pesquisadores se mantem ativo através do Círculo, propositor de arte coletivo que já traz, em seu bojo, a participação da comunidade na presença de duas artistas. A aproximação com as instituições escolares se faz como alternativa a essa intervenção policial, no investimento em processo já continuado de educação que desejamos fortalecer. A partir de maio de 
2011 estivemos em contato com três instituições escolares, a Escola Municipal Humberto de Campos, com a Creche Escola Nação Mangueirense e com o Centro Intensivo de Educação Popular (CIEP) Nação Mangueirense.

Junto ao CIEP, nos envolvemos com o grupo de dança Nação Mangueirense e realizamos, conjuntamente, uma intervenção artística na Praça da Democracia no campus UERJ Maracanã. Inauguramos a praça em outubro, contando também com a presença de quatro turmas da escola Humberto de Campos. Unimos os grupos em uma obra única, compondo um encontro dos estudantes e docentes das três instituições: UERJ, CIEP N. M. e E. M. H. C.

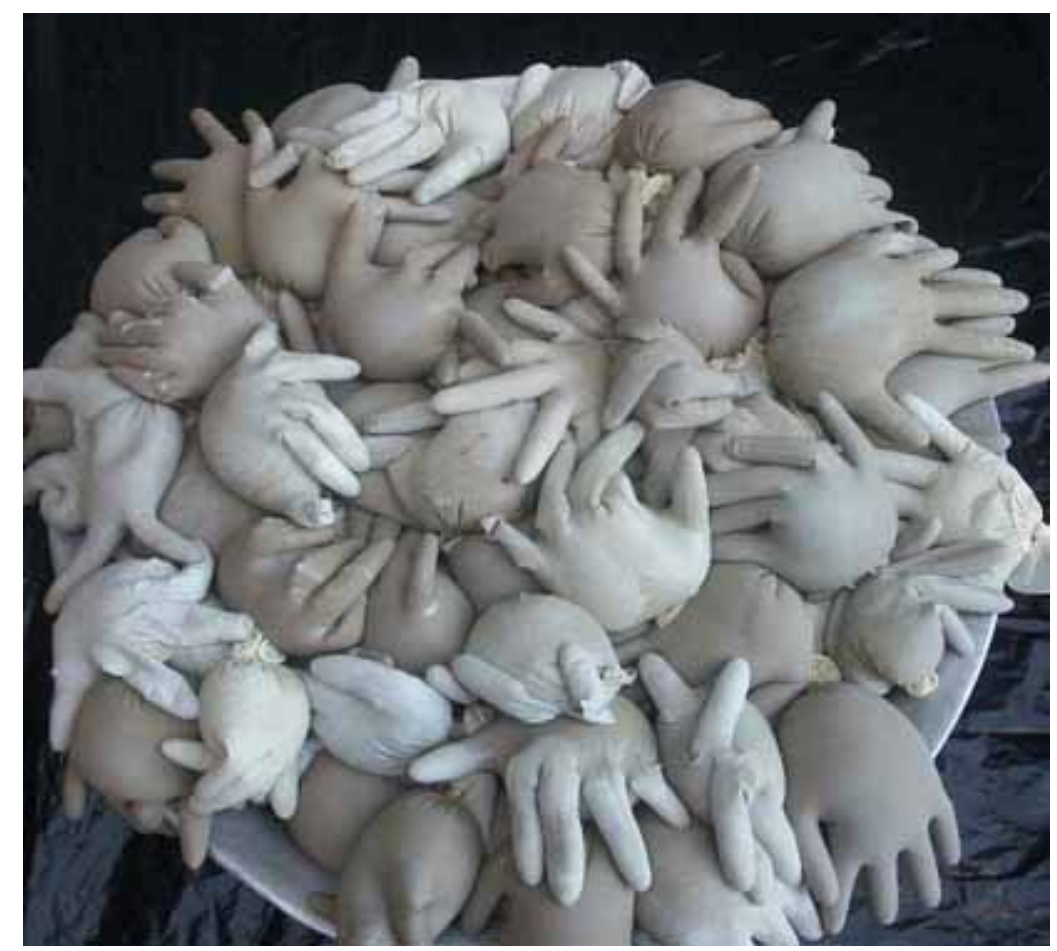

Fig 3. A Mão Amiga - objeto relacional. Há sempre uma forma redutora, um modo de se fazer da mulher, um pedaço, reificando-a, tornando-a um objeto parcial. Nesse sentido, olhar os dedos significou ir ao encontro dessas menores formas de diluição. Foi essa a nossa motivação. Olhar e brincar com os dedos nos levou a descoberta de seus poderes comunicativos, de seus modos expressivos. Ao chegarmos à mão, nosso mais recente movimento, encontramos uma força inexplicável traduzida para o carinho e a aceitação. Fonte: arquivo da pesquisa. 
Planejamos agora, um maior comprometimento com a creche escola Nação Mangueirense, no desenhar um percurso de grande extensão: riscamos uma linha que parte do berçário e chega à pós graduação. Nos propomos a pensar/agir sobre a partilha do sensível (Rancière, 2005) nesse rol institucional, tendo em vista a sua relação com as disposições internas da comunidade. Uma das questões a serem abordadas é a condição de diálogo entre os docentes e os pais, em que ambos, pais e professores, como educadores, se reconhecem nesse papel e de que modo entendem a participação do outro.

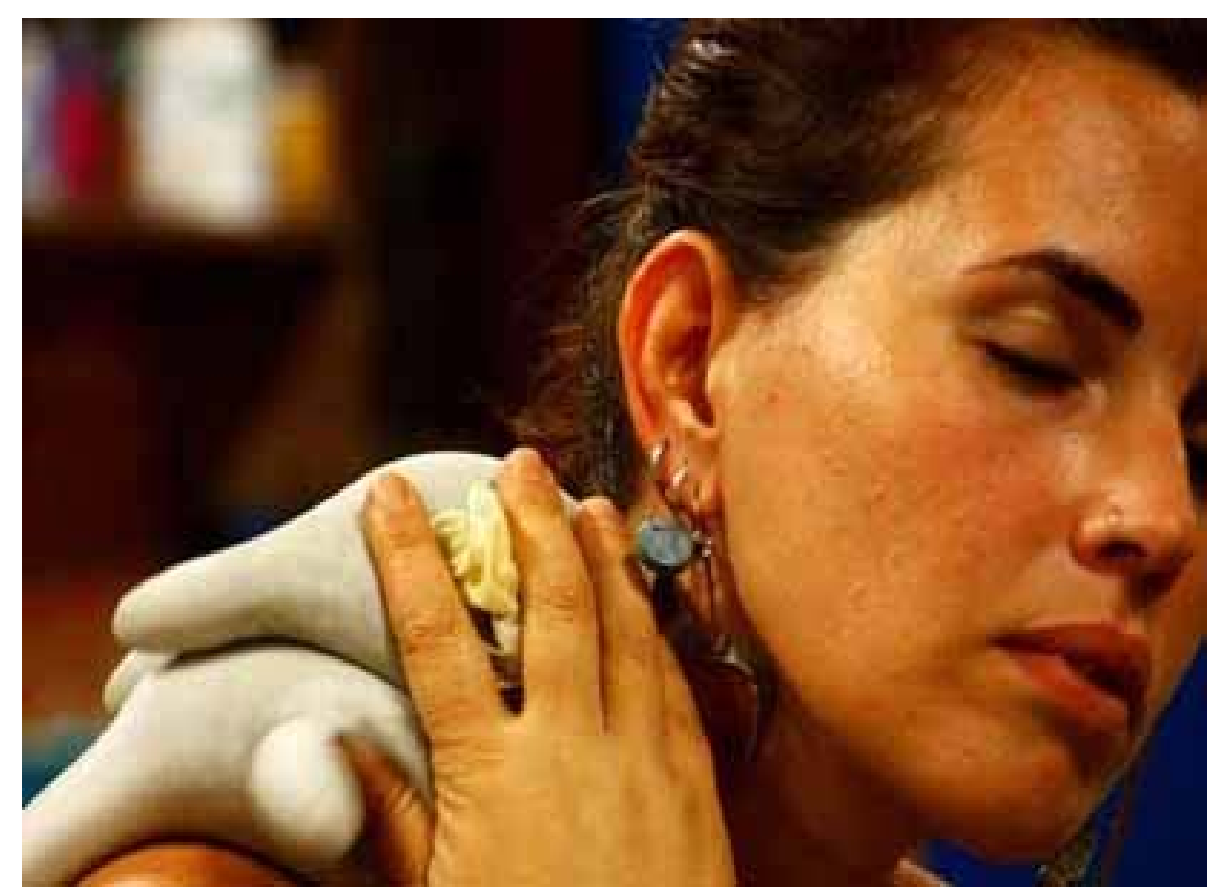

Fig 4. Afago da Mão Amiga, objeto relacional. Mão Amiga, forma acolhedora, dócil, adaptativa, refrescante, sutil. O objeto relacional Mão Amiga é objeto construído de modo simples: luvas de látex preenchidas com argila em estado líquido. É capaz de adquirir calor, sendo possível a troca térmica entre corpo e objeto (passando assim de refrescante a calorosa). Como é maleável, se adapta aos contornos do corpo, se encaixando de modo delicado, suave, nas formas com as quais toca e sobre as quais pousa. Fonte: arquivo da pesquisa.

As disposições de Humberto Maturana no entendimento do valor que devemos dar ao emocionar na educação das crianças e o olhar para o interior de comunidade à qual pertencem são pontos de força nesse trabalho: 
As mudanças culturais só acontecem quando ocorre uma modificação no emocionar que assegure a conservação da nova rede de conversações que constitui a nova cultura. Como isso acontece? Há variações segundo distintas circunstâncias históricas, mas a conservação do novo emocionar deve ocorrer por meio das crianças da comunidade. Dessa maneira, o modo como vivemos com nossas crianças é, ao mesmo tempo, a fonte e o fundamento da mudança cultural e o mecanismo que assegura a conservação da cultura à qual se vive. (Op. Cit., p. 23)

Esses diálogos são fundamento no espaço liminar onde o público encontra o privado, pois as escolas, na comunidade, representam o poder público. Esse relacionamento, agora crispado pela presença massiva de policiais, revela o inquietante estado no qual comunidade e poder público se deparam. Legada à creche a tarefa de apoiar as mães no cuidado das crianças em tenra idade, papel que exige proximidade com a família, esta se encontra em posição privilegiada para mediar a mudança social para além da violência.

Os enunciados políticos ou literários fazem efeito no real. Definem modelos de palavra ou de ação, mas também regimes de intensidade sensível. Traçam mapas do visível, trajetórias entre visível e o dizível, relações entre modos de ser, modos do fazer e modos do dizer. Definem variações das intensidades sensíveis, das percepções e capacidades dos corpos. (Rancière, Op. cit., p. 59)

\section{Expandindo o círculo pessoal, redimensionando a esfera pública}

A forma geral de nosso trabalho gira em torno do conceito de arte pública (Silva, 2005), aliando-o ao modelo relacional, dando prioridade ao sentido de compartilhamento e de troca na produção de arte (Borriaud, 2009). Isto ocorre por meio de uma vertente muito clara no que concerne ao papel educativo do projeto, que procura atuar de forma menos diretiva e mais integradora, menos instrucional e mais dinamizadora. 


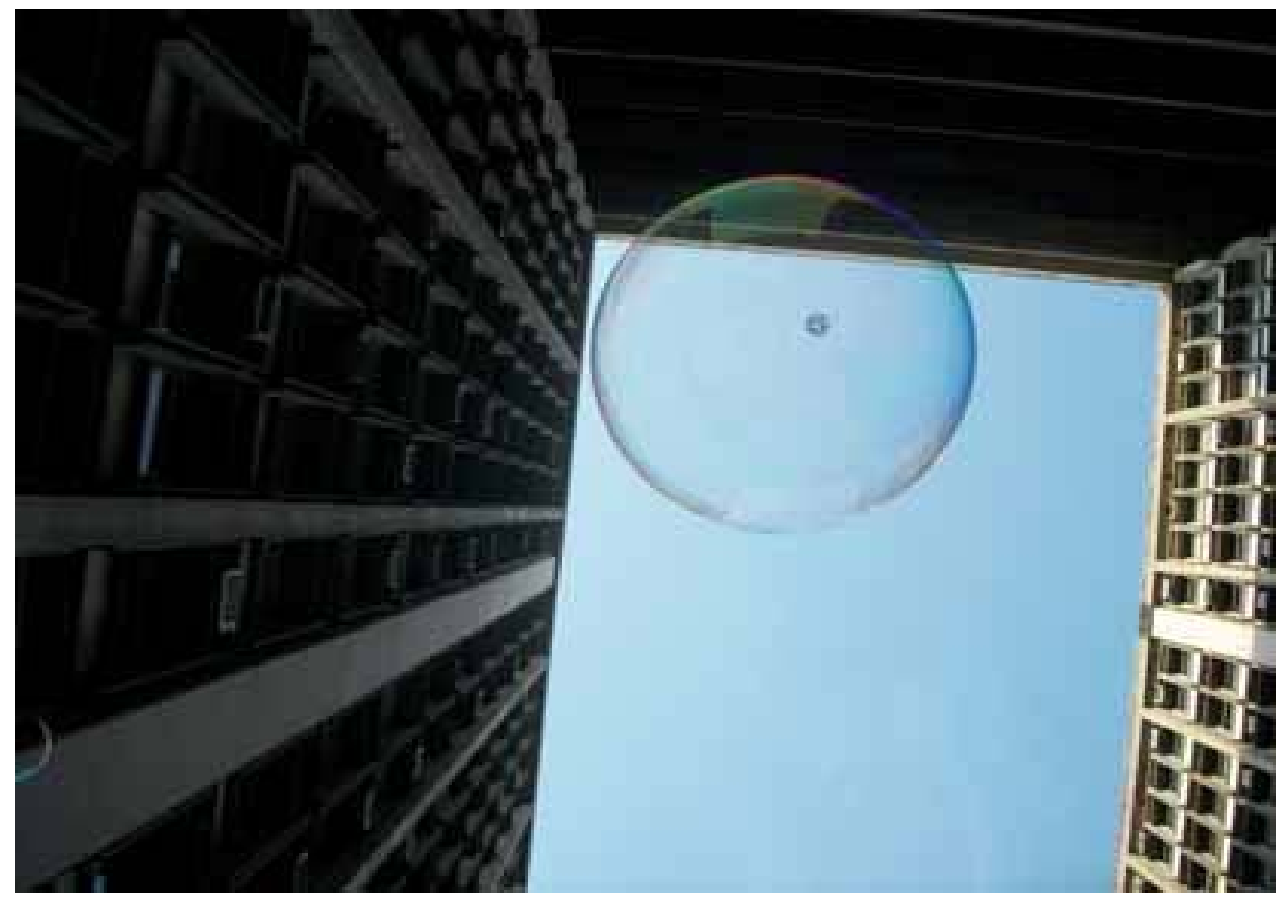

Fig 5. Na Praça da Democracia, no campus Maracanã, produzimos leveza e colorido. Fonte: arquivo da pesquisa.

Notadamente voltados na observação desse fluxo entre culturas, das de lá (Mangueira) e as de cá (UERJ), elaboramos a criação do Círculo numa proposta de formação de um grupo de compartilhamento e permuta integrando mulheres desses dois locais com a franca disposição de viver arte. O objetivo central é criar um espaço de entrosamento, de troca e de apoio mútuo entre mulheres, atentando para o fato da estratégica força que as mulheres exercem na comunidade mangueirense como líderes e arrimos familiares e, por outro lado, fazendo sentido também pela parte da constelação artística contemporânea, que incide na delicada posição das mulheres artistas, que possuem uma relativa e subordinada entrada nas instituições de arte (FRADE, 2009). São essas mulheres artistas, pesquisadoras e educadoras do coletivo $O$ Círculo de Arte da Terra que estão dinamizando as oficinas, promovendo intervenções e projetando as ações do Arte Viva.

Ao início propusemos a série de encontros exploratórios iniciais nas oficinas de criação. As primeiras atividades foram dedicadas à descoberta do barro, aos processos de sua modelagem, ao reconhecimento do grupo e da escola como espaço afetivo irradiador. A argila como prima mater por excelência, uma imagem que apreciamos pela poética imaginante (BACHELARD) que ela conduz, abrindo caminho para outras práticas artísticas. 
A vontade é bem mais administrada por um devaneio que une o esforço e a esperança, por um devaneio que já gosta dos meios, independentemente de seu fim. O devaneio ativo alimenta a coragem através dos encorajamentos constantemente verificados no trabalho. (2001, p.78)

A introdução de práticas que derivam da Arte da Terra e processos afins se propõe como veículo para a ação educativa em arte envolvendo questões sociais, ambientais, familiares e pessoais. O foco no macrocosmo - A Terra - não evita o lidar com o entorno e a dimensão pessoal da existência. O individuo é visto, deste modo, como ligado ao meio que o cerca, sujeito sócio e ambientalmente vinculado. A argila, material terroso e maleável, se apresenta como matéria básica para esse projeto por sua capacidade de atender ao necessário movimento de aproximação com a natureza - humana e física - ao se indicar sua massa como corpo plástico e sua fácil reintegração na natureza, sendo ecologicamente benéfico. Mas não apenas com esse material se pensa a Arte Viva da Terra, pois desenvolvemos, no trabalho de arte do Círculo, o desenho, a pintura e colagem, a fotografia digital, a performance, a poesia e tantas outras linguagens poéticas, processos que nascem convocados pelo próprio grupo no seu próprio fluxo de constituição de imagens expressivas e reflexivas. Essas não se materializam apenas no barro, mas se articulam a partir de uma fidelidade`a terra, aproximadamente ao que inspirava Nietszche.

O que ainda haverá de natural em nós, do que não nos distanciamos o suficiente para ainda nos reconhecermos ali? Trata-se de (re) encontrar conscientemente o que tanto ansiamos inconscientemente, o "retorno ao orgânico" (...) Que experiência é essa? Podemos denominá-la "a última aventura humana", a última aventura humana sobre a terra, nossa maior experiência, a que nos justifica a vida propriamente humana, donde vem ser o super-homem o sentido da vida do homem sobre a terra - o "sentido da terra", portanto, que se encarna no homem. (Guerra Filho, 2003, p.157)

\section{Ações educativas em arte ambiental - a semeadura}

Os processos de criação plástica operam como dispositivo no ativar a expansão do imaginário que alimenta os sujeitos envolvidos, recorrendo a diálogos e jogos para tornar o processo vivo no interior de um corpo relacional dinâmico. É 
onde a modelagem em argila significa a captura da condição do ser humano como ser "em estando", usufruindo de sua condição polimorfa. "A rigor, não há "ser" humano, mas apenas "sendo" humano."(GUERRA FILHO, 2003).Depois é se colocar à deriva, na larga experimentação plástica, onde ocupa importante papel a seleção de materiais que possam estar conectados com as experiências das próprias crianças, como objetos descartados e outros materiais de reciclagem. $\mathrm{O}$ que torna esse trabalho significativo é seu escopo ampliado de arte, que busca envolver as questões ambientais no aporte subjetivo de formação dos sujeitos, numa ecosofia (Guatarri, 2004) intensa a se desenvolver coletivamente e de forma integrada com os próprios movimentos da creche escola Nação Mangueirense.

A questão será literalmente reconstruir o conjunto das modalidades de serem-grupo. E não somente pelas intervenções "comunicacionais" mas também por mutações existenciais que dizem respeito à essência da subjetividade. Nesse domínio, não nos ateríamos às recomendações gerais mas faríamos funcionar práticas efetivas de experimentação tanto nos níveis microssociais quanto em escalas institucionais maiores. (Guatarri, 2004, p. 16)

Elencamos alguns modelos de ações educativas planejadas em articulação com os espaços educativos e propostas da equipe pedagógica da instituição e estamos em contato direto com as crianças. Trouxemos a eles o contato com a argila a partir de narrativas diversas.

Em constante diálogo com a direção da creche-escola, preparamos os recipientes para o plantio das novas mudas para continuar a compor os desenhos dos jardins e estamos em fase de estudo sobre o terreno onde fizemos o primeiro plantio. Já iniciamos a semeadura. 


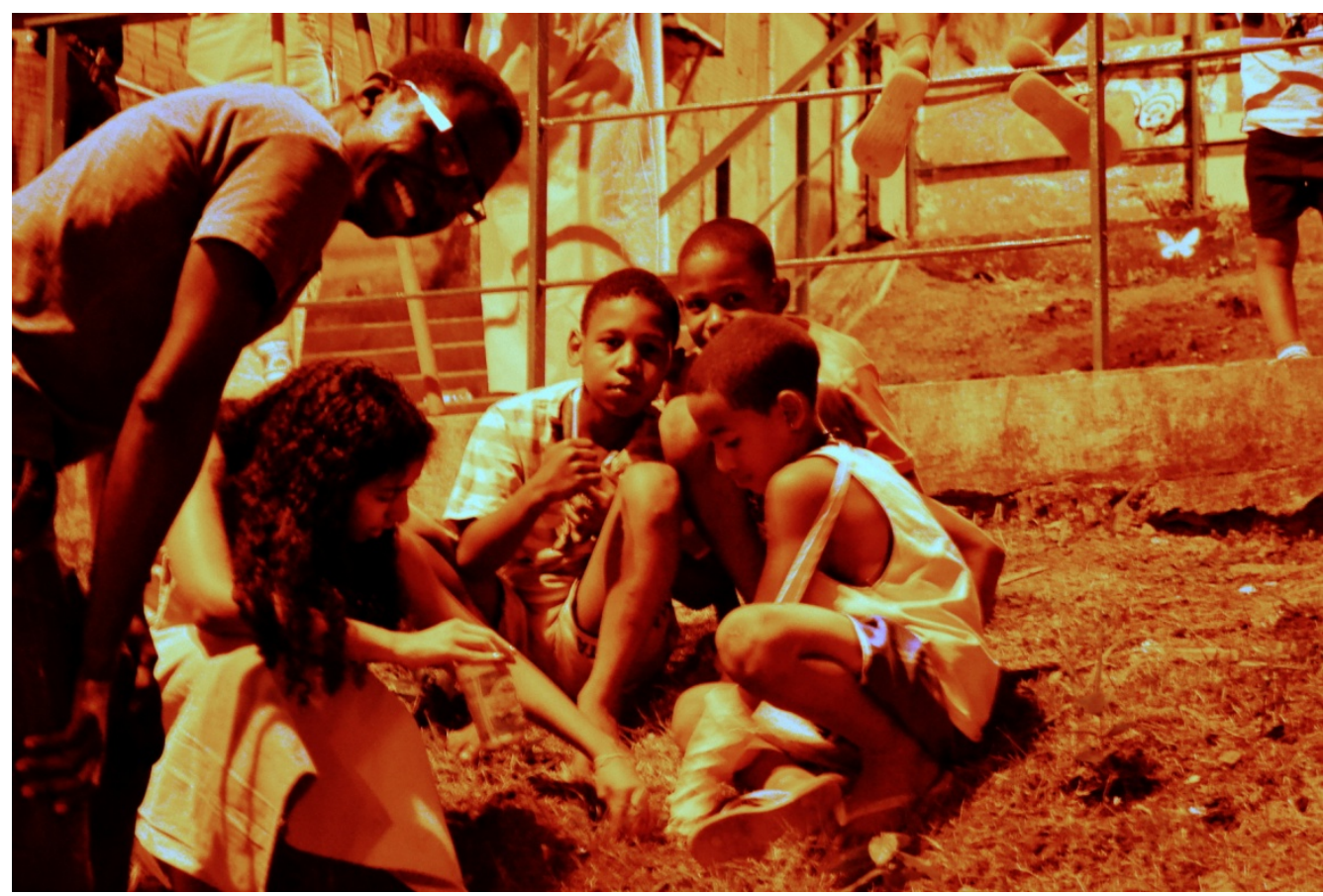

Fig 6. À luz de mercúrio, amarelada, torna a Rua Icaraí um ambiente peculiar quando cai a noite: as cores se desfazem. A obra Lembrancinhas, revisitada pelo projeto Jardim das Delícias, instaura criação na terra em narrativas sobre paisagens vividas. É a ação de semearmos juntos que produz essa conversação sobre o que é comum e o diferente a cada um de nós e que, pouco a pouco, configura o que podemos considerar com segurança como sendo de todos, pois produzimo-lo juntos. Fonte: arquivo da pesquisa.

Nesse momento, cabe o levantamento de trabalhos de artistas que envolvem a relação ser humano na constituição de ambientes educativos, lugares verdes e espaços de relação. As obras de Giuseppe Penone, Agnes Denes, Mario Merz, Hans Haccke entre outros artistas, dos quais os brasileiros Hélio Oiticica, Lygia Clark, e atualmente o coletivo Poro, José Kinceler e Isabela Sielski, e ainda tantos outros a identificar nesse levantamento, apresentam formas que nos revelam modos de atuar na perspectiva de uma arte ambiental.

Sob esse aspecto, e pelo fato de estarmos atuando na Mangueira, é que a obra de Hélio Oiticica tem sido intensamente revista. Quando o artista estudava a obra Merzbau de Schwitters como "construção aberta" distinguia formas fundantes do modo participativo no ambiente projetado: "Não condicionar a vivência ou o sentido de um recinto, mas dar-lhe aberto para a construção dele pela vivência participativa" (Oiticica, 1986, p.120). 
Oiticica seguia no pensar a condição de uma arte que se afastaria radicalmente dessa ideação pura do artista e que em sua obra se identificaria com a relação ativa e não condicionadora do púbico, este co partícipe. Esta subsistiria no caráter de abertura e a qual ele identificava como arte ambiental: "Há então, longa e paulatinamente, a passagem desta posição de querer criar um mundo estético, mundo-arte, superposição de uma estrutura sobre o cotidiano, do comportamento humano, e transformá-lo por suas próprias leis, por proposições abertas, nãocondicionadas, único meio possível como ponto de partida para isso." (Idem)

As obras de Kinceler, artista que consideramos mais próximo ao nosso trabalho, produzindo no caminho da arte relacional complexa (2008), revelam formas de criação onde o papel do artista segue para o diálogo, em operação continuada e persistente na geração de proximidade e entendimento mutuo junto a comunidades. Projetamos a obra Jardim das Delícias como uma rede de jardins e pomares, contando a primeira ação com a criação do Jardim da Tia Neuma na Rua Icaraí, onde a sensibilidade do público começa a ser ativada de modo delicado. Os artistas educadores se posicionam em relação simétrica e na condição da escuta.

A transformação do meio como propósito, no desejo compartilhado de criar na Mangueira um jardim como espaço de jogo, de encontro lúdico, é até lá compartilhamento de sonho emotivo de onde muitas idéias pululam ao se pensar no que poderia estar a se desenvolver ao ar livre. Nesse sentido é que os projetos de artistas estão sendo observados com vagar, no aprendizado da experiência que constituíram e pelas quais desejamos nosso amadurecer. O trabalho de Elvira de Almeida (1997), a que ela denomina "arte lúdica", e que consiste, em linhas gerais, na construção pelo modo colaborativo de brinquedos e mobiliário de praças paulistanas, tem sido objeto de reflexão e deleite constante. Almeida relata os primeiros passos para a criação das suas obras que se dá na percepção dos movimentos do lugar. A partir disso, a força se daria na operação de ampliação dessa dinâmica: 
O ambiente lúdico desejado para essa área seria propício à liberdade de expressão, um cenário de brincar onde, de uma forma bastante natural e dinâmica, as crianças passassem de um brinquedo a outro conforme o enredo da história que inventassem. O espaço sugerido por cada escultura iria sugerir sua continuidade com o conjunto do ambiente como um todo, e este deveria ser amplo e aberto, um convite ao movimento. ( p.86)

As intervenções urbanas de Lucimar Bello estão também sob nossa mirada. As três grandes qualidades professadas pela artista - simpatia, alegria e delicadezas - nos mantém sob direcionamento:

Simpatia, como produção de subjetividades, afetações intensivas, estratégias de vibração em conjunto, uma forma do conhecimento a se fazer (David Lapoujade); alegria, como estados de "bons encontros" (Espinoza); delicadezas, como dispositivos, na arte contemporânea, de partilha, de doação, de encontros des-interessados e des-mercantilizados. (Frange, 2011, p.115)

O primeiro ponto escolhido para esse deflagrar da "pracialidade" (termo encantador de Bello) mangueirense foi a Rua Icaraí, onde vamos pouco a pouco movimentando cada pequeno declive. Em canteiros abandonados, estamos plantando mudas e sementes. E nas cinco plataformas, passando em gerar "pracinhas", lugares que pretendem agregar moradores e passantes. Em duas delas, com mesas e bancos de cimento, partimos para atuar com mini oficinas de desenho e modelagem em argila. $O$ terreno que pretendemos ocupar progressivamente com a criação do Jardim da Tia Neuma, este gesto significando modelagem de lugares, envolve toda a rua e seus moradores. Estamos recuperando o espaço para torná-lo campo de encontro, de prazer e alegria e para isso vamos interagindo com as pessoas. Consideramos que ali os idosos poderiam se encontrar e contar histórias, fazendo valer a memória do lugar, as crianças descobrindo formas e criando movimentos, jogando livremente, as famílias recuperando o terreno degradado, trazendo contentamento e trocando experiências. São estas algumas das predisposições manifestadas e que desejamos ampliar pelas sugestões de seus frequentadores. 


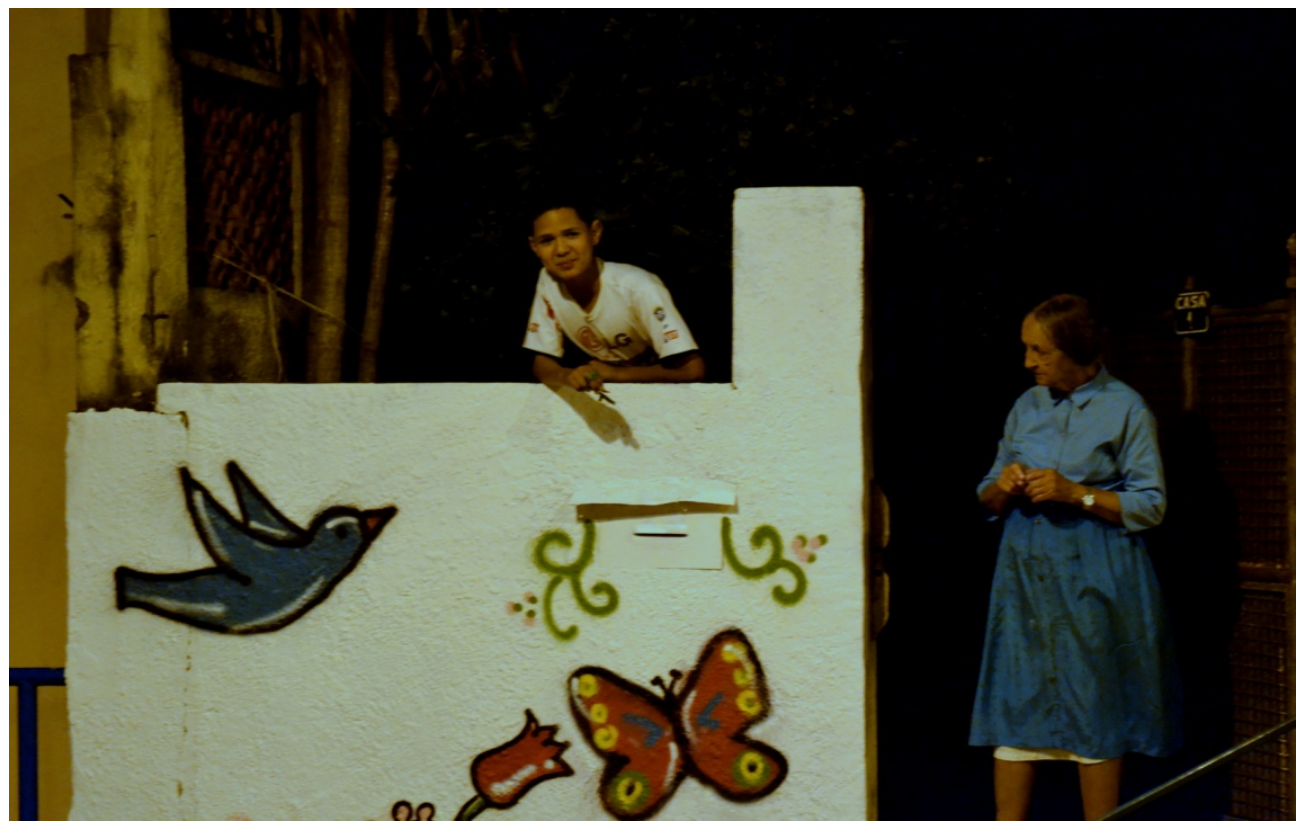

Fig 7. Moradores observam, comentam e interagem com o trabalho de arte grafitti. A primeira intervenção nas casas foi efusivamente recebida: outros moradores de áreas mais afastadas encomendaram painéis para suas casas. Focando ainda na pequena rua, agora pretendemos ir subindo o morro e colorindo esse percurso. Arquivo da Pesquisa.

Sabemos que nesse processo, muitas reuniões e conversas serão necessárias para seguirmos transformando esses intentos em decisões comuns. E, depois, o partir juntos para o trabalho de dar a esse anelo maior corpo e substância. Nesse sentido, nos lançamos em experiências de criação efêmeras e múltiplas, disponíveis para os acontecimentos imprevistos e para o aproveitamento das oportunidades que as instituições oferecem. Nos dispomos, assim, ao serviço de seus propósitos, buscando colaborar em seus intentos próprios. Com isso, cada participante segue descobrindo sua amplitude na condição ativa da cidadania e se lança em uma extensão para além desse contexto restritamente cívico, vinculando-o a um âmbito profundamente humano. 


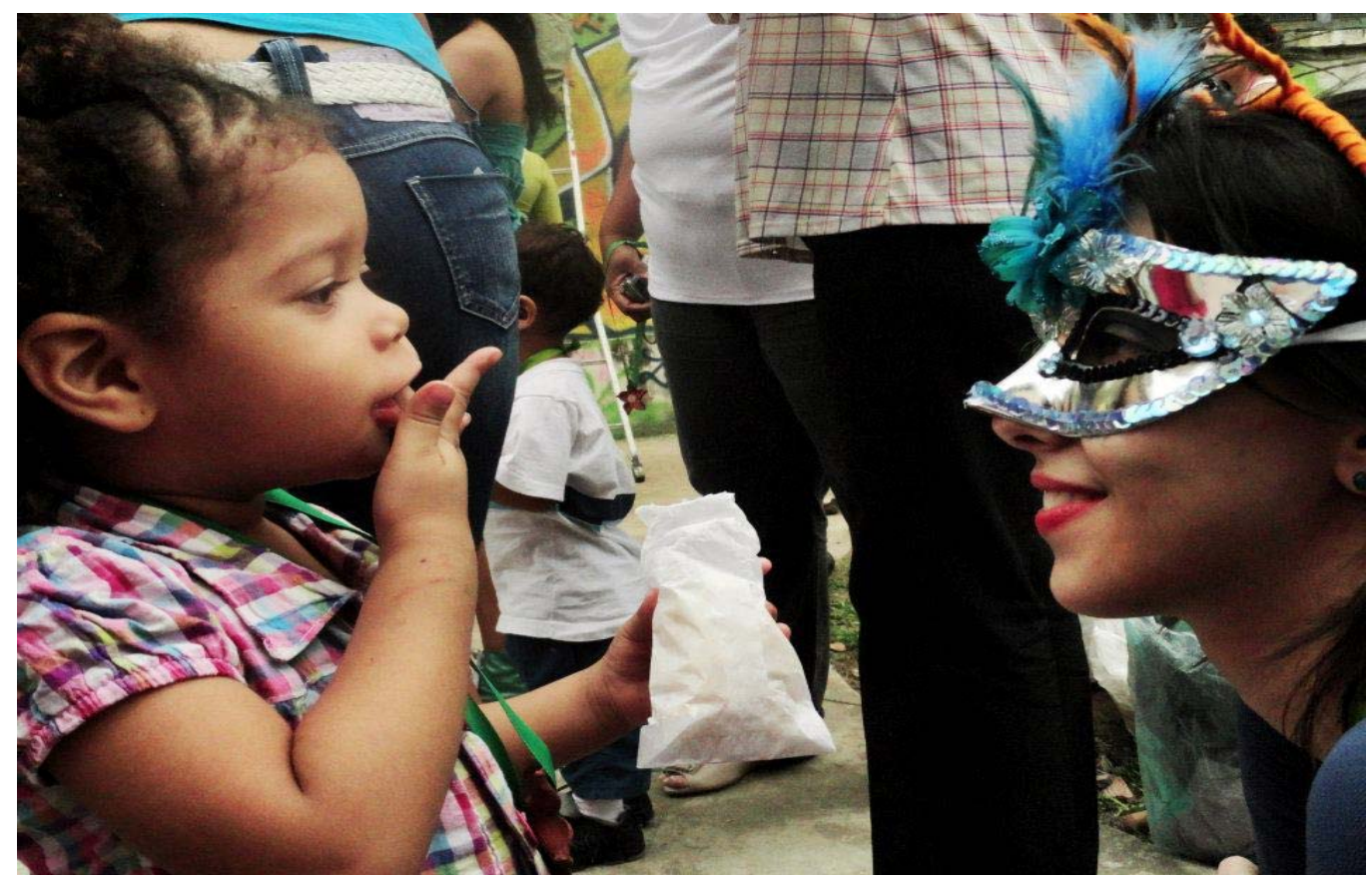

Fig 7. Largarella,uma de nossas últimas obras, uma narrativa dramatizada, abriu contato intenso com a comunidade escolar da CENM: as crianças foram um público desafiador, onde queríamos uma troca direta para deflagrar o projeto Jardim da Tia Neuma. Na trama, uma largarta sofre pela sua indeterminação e voracidade até se encontrar borboleta. Fonte da pesquisa.

\section{REFERÊNCIAS BIBLIOGRÁFICAS}

ALMEIDA, E. Arte Lúdica. São Paulo: EDUSP, 1997.

BACHELARD, G. A Terra e os Devaneios da Vontade. São Paulo, Martins Fontes, 2001.

BOURRIAUD, Nicolas. Arte Relacional. São Paulo: Martins Fontes Ed., 2005.

BRANDÃO, C.R. (Org.). Pesquisa Participante. 3a ed. São Paulo: Brasiliense, 1981.

CASTRO, Manuel Antônio. ARTE: Corpo, Mundo e Terra. Rio de Janeiro, Ed. 7 Letras, 2009.

FRADE, Isabela, HENCK, Joice e SARAIVA, Leticia. Da Esfera Relacional à Arte Pública - o projeto Terra Doce na Via UERJ - Mangueira. Belo Horizonte, Editora C/ Arte, 2011. p. 509 $-518$.

FRANGE, Lucimar Bello. Cidades desenhantes - um desnorte. In Entre Territórios. Salvador: UFBA, 2011. 
FREIRE, Paulo. Pedagogia da Autonomia. São Paulo: Editora Paz e Terra, 1996.

GUERRA FILHO, Willis Santiago. A última aventura humana sobre a terra. In A fidelidade à terra. FEITOSA, Charles et alli. Rio de Janeiro: DP\&A Editora, 2003. p. 155 162.

KINCELER, José. As noções de descontinuidade, empoderamento e encantamento no processo criativo de "Vinho Saber - arte relacional em sua forma complexa in Anais XVII Anpap. Florianópolis, UDESC, 2008.

MATURANA, Humberto e VERDEN-ZOLLER, Gerda. Amar e Brincar - Fundamentos esquecidos do humano. São Paulo: Palas Atenas, 2009.

OITICICA, Hélio. Aspiro ao Grande Labirinto. Rio de Janeiro: Editora Rocco, 1986.

RANCIÉRE, Jacques. A Partilha do Sensível. São Paulo: Editora 34, 2005.

Isabela Frade - artista e educadora, doutora em Comunicação pela ECA/USP. Docente do PPGARTES/UERJ, Procientista FAPERJ; coordenadora do projeto de extensão Cerâmicaviva. Lidera o Grupo de Pesquisa - CNPq Observatório de Comunicação Estética. Coordena o coletivo de arte O Círculo. isabelafrade@gmail.com 